\title{
Inhibition of intraocular fibrin formation with annexin $\mathrm{V}$
}

P Chollet, F Malecaze, F Hullin, P Raynal, J L Arne, V Pagot, J Ragab-Thomas, H Chap

\begin{abstract}
Annexin $\mathbf{V}$ is a member of the calcium- and phospholipid-binding proteins, known to have an antithrombotic effect. For the first time, we have tested its ability to prevent intraocular postoperative fibrin formation in a standardised rabbit model and compared its effect with that of heparin. Annexin V, $20 \mu \mathrm{g}$ and $60 \mu \mathrm{g}$, injected in the anterior chamber postoperatively, significantly reduced the area of the fibrin clot and its time to clearing. Annexin $V$ appeared to be as efficient as heparin. It probably acts by preventing phospholipids from playing their role in the coagulation cascade which leads to fibrin formation. Furthermore, annexin $\mathrm{V}$ has an anti-inflammatory effect by protecting phospholipids from phospholipase $A_{2}$ activity. Therefore, annexin $V$ might be considered as a new therapeutic agent acting both on fibrin formation and inflammatory processes. (Brf Ophthalmol 1992; 76: 450-452)
\end{abstract}

After intraocular surgery, a more or less intense fibrinous reaction can occur. This intense fibrinous reaction prevents adequate postoperative examination and may lead to pupillary block glaucoma. Fibrin results from the extravasation of activated coagulation factors due to disruption of the postoperative blood aqueous barrier. An attempt to lessen its occurrence usually involves the use of topical or even systemic steroids which would theoretically act by stabilising vascular membranes; on the other hand, heparin is well known to inhibit coagulation and therefore fibrin formation. Johnson $e$ $a l^{1}$ have already shown its ability to prevent intraocular fibrin formation after surgery. However its use is not without complication in patients since it may enhance the frequency of intraocular bleeding.

Annexin $\mathrm{V}$ is one of the seven members of the newly isolated annexin family. All of these proteins share the ability to bind to phospholipids in a calcium-dependent manner. ${ }^{34}$ The precise function of annexin $\mathrm{V}$ remains uncertain, but it has been shown to have two main biological properties, resulting from this biochemical feature: an anti-inflammatory effect through inhibition of phospholipase $\mathrm{A}_{2}{ }^{4}$ and an antithrombotic effect through inhibition of the coagulation cascade, whose activation leads to fibrin formation. ${ }^{\mathrm{s}}$
In this study we investigated the effectiveness of intracameral annexin $\mathrm{V}$ in preventing fibrin formation in a standardised rabbit surgical model and compared it with that of intracameral heparin.

\section{Materials and methods}

New Zealand white rabbits weighing $2 \cdot 0$ to $2 \cdot 5$ $\mathrm{kg}$ were used in this study. All animals were treated according to the Association for Research in Vision and Ophthalmology resolution on the use of animals in research. Rabbits were anaesthetised with an intramuscular injection of $50 \mathrm{mg}$ ketamine. Surgical procedures were according to Johnson $e t$ al $^{1}$ with few modifications: a sclerotomy was made $1 \mathrm{~mm}$ posterior to the limbus and a central vitrectomy was then performed with lactated Ringer's as posterior infusion solution. No lensectomy was performed since lens persistence is considered to localise the fibrin clot to the anterior chamber and therefore to facilitate the estimation of postoperative fibrin reaction. ' Five minutes later, cyclocryotherapy was performed. A cryoprobe was placed at the limbus at the 3, 6, 9, 12 o'clock positions and freezing was performed for 45 seconds at $-80^{\circ} \mathrm{C}$. An anterior chamber puncture $(100 \mu \mathrm{l})$ was then made, followed by an intracameral injection of annexin V, heparin, or Ringer's lactated solution: 18 rabbits underwent an injection of annexin $\mathrm{V}$ : $5 \mu \mathrm{g}(n=6), 20 \mu \mathrm{g}(n=6)$, or $60 \mu \mathrm{g}(n=6)$. A second group $(n=18)$, the controls, was injected with lactated Ringer's solution.

Six rabbits were operated simultaneously on both eyes. At the end of surgery, one eye was injected with $20 \mu \mathrm{g}$ of annexin $\mathrm{V}$, the other one with 15 IU heparin.

All injections were diluted with lactated Ringer's solution so that the final volume was $100 \mu \mathrm{l}$. Care was taken to avoid contact with any structure of the anterior chamber. No antibiotic or anti-inflammatory treatment was used postoperatively.

Rabbits were then examined daily: after an instillation of topical anaesthesic, the anterior chamber was examined with a surgical microscope and was assessed for the presence or absence of fibrin. Fibrin tended a form a contiguous white amorphous clot or, in less obvious reactions, led to a decrease in the fundus red reflex or an obscuration of the iris details. Fibrin clot reaction was evaluated in a similar manner to that used by Johnson et al. ${ }^{1}$ 
Two parameters were taken into consideration: (1) Fibrin clot area on the first postoperative day. The anterior chamber was divided into four quadrants. Fibrin clot was graded on a scale of $1+$ to $4+$. A $1+$ clot involved an area up to one quadrant; a $2+$ clot involved an area up to two quadrants: a 3+ clot involved an area up to three quadrants, and a $4+$ clot involved an area up to four quadrants.

Light fibrin reactions, obscuring iris details, with no 'real' clot, were recorded as grade $1+$.

(2) The time until clearing of the fibrin clot. It was recorded as the first postoperative day on which no more fibrin was to be seen. There were two examiners for all experiments, which were performed in a double-blind manner.

The annexin $\mathrm{V}$ used in this study was purified in our laboratory from human placenta, according to the procedure described by De $e t$ $a l .^{6}$

To evaluate the effectiveness of annexin $\mathrm{V}$ in reducing postoperative intraocular fibrin, we used the Mann-Whitney $U$ test and the Wilcoxon-signed rank test to compare its efficacy with that of heparin.

\section{Results}

Surgical procedure resulted, in all cases, in a fibrinous reaction on the first postoperative day.

EFFECTIVENESS OF ANNEXIN V IN INHIBITION OF POSTOPERATIVE FIBRIN CLOT

Annexin V-injected eyes, at doses of more than $5 \mu \mathrm{g}$, had less fibrinous reaction and a shorter time to clearing than the control eyes.

In Figure 1 results are expressed as the mean of fibrin clot areas at day 1 for control eyes and annexin V-injected eyes. There was no statistically significant difference between control and $5 \mu \mathrm{g}$ of annexin $\mathrm{V}$-injected eyes, but fibrin clot areas in the eyes treated with 20 or $60 \mu \mathrm{g}$ of annexin $\mathrm{V}$ (respectively 2.0 and 1.7 quadrants) were lower than the controls in a statistically significant manner $(\mathrm{p}<0 \cdot 01)$.

The average days to clearing are shown in Figure 2. Fibrin clearance in control and 5, 20, and $60 \mu \mathrm{g}$ of annexin $\mathrm{V}$-injected eyes were respectively $4 \cdot 7,3,2 \cdot 3$, and $2 \cdot 8$ days. Differences

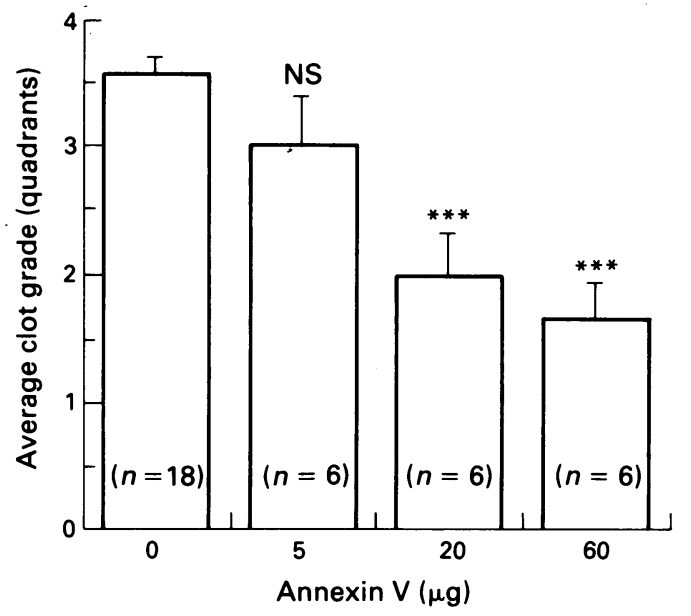

Figure 1 Fibrin clot areas on the first postoperative day. Results are expressed as the mean (SE) of the fibrin clot areas in control. NS=not significant; ${ }^{\star \star} p<0.01$. between control and treated eyes were statistically significant at each dose $(p<0.05$ and $p<0.01)$.

\section{COMPARISON OF ANNEXIN V VERSUS HEPARIN}

The results of the comparison of the effectiveness of annexin $\mathrm{V}$ versus heparin treatment are summarised in Table 1 . No statistically significant difference was found between the two treatments.

\section{Discussion}

This study shows the effectiveness of annexin $\mathrm{V}$ in inhibiting fibrinous postoperative reaction. Intracameral injections of 20 or $60 \mu \mathrm{g}$ of annexin $V$ resulted in a less important fibrinous reaction than in the control eyes, and this reaction cleared in a shorter time. Injections of $5 \mu \mathrm{g}$ of annexin $\mathrm{V}$ had the same results but the difference between treated and control eyes was not significant for the starting postoperative fibrinous reaction.

Exuberant fibrinous intraocular exudates are a severe complication in vitrectomy surgery or anterior segment surgery and many studies have already investigated the ability of different treatments to prevent or to treat fibrin formation. This was achieved mainly with standard heparin' 2 or low molecular weight heparin fractions,? or with tissue plasminogen activator in the case of treatment. ${ }^{89}$ In our study we chose to inject $15 \mathrm{IU}$ of standard heparin in the anterior chamber, since it had been shown to be the most effective dose in this protocol.' We were unable to show any difference between the annexin V and heparin treated eyes.

Annexin $\mathrm{V}$ was already known to have in vitro $^{51011}$ and in vivo ${ }^{12}$ anticoagulant properties but had never been used in such a model of fibrin formation. The method by which annexin $\mathrm{V}$ reduces fibrin formation remains unclear. This effect might be explained by its ability to bind to phospholipids in a $\mathrm{Ca}^{2+}$-dependent manner, a main biochemical feature of all annexins. Phospholipids would then be unable to play their role in the activation of factor $\mathrm{X}$ and prothrombin. Thus conversion of fibrinogen into fibrin would then be impaired.

Preoperative and postoperative bleedings are

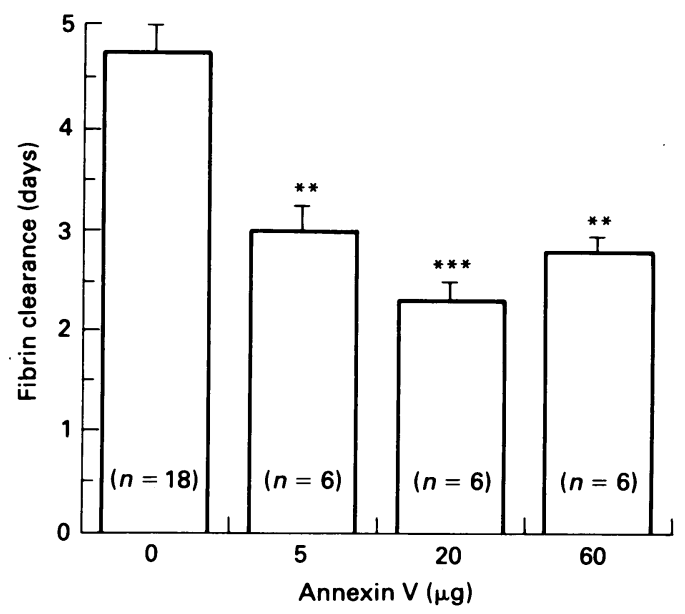

Figure 2 Time to clearing of the fibrin clot. Results are expressed as the mean $(S E)$ of the number of days to clearing 
Table 1 Efficacy of annexin $V$ versus heparin

\begin{tabular}{lll}
\hline Treatment & $\begin{array}{l}\text { Average clot grade } \\
\text { Mean (SE) }\end{array}$ & $\begin{array}{l}\text { Average days to } \\
\text { clearing } \\
\text { Mean (SE) }\end{array}$ \\
\hline Heparin $(15 \mathrm{IU})$ & $2 \cdot 7(0 \cdot 4)$ & $2 \cdot 8(0 \cdot 3)$ \\
Annexin V $(20 \mathrm{\mu g})$ & $2 \cdot 5(0 \cdot 5)$ & $2 \cdot 6(0 \cdot 2)$ \\
\hline
\end{tabular}

the main reason why standard heparin is difficult to use as a treatment. This explains the great interest aroused by low molecular weight heparin derivatives: they are supposed to lower the occurrence of bleeding while preventing fibrin formation with the same efficacy as standard heparin. In a recent study Iverson $e t a l^{7}$ have shown the efficacy of low molecular weight heparin derivatives in the prevention of intraocular fibrin formation occurring after lensectomy, vitrectomy, and retinotomy in a rabbit model. They have effectively noted no increased tendency to postoperatively bleeding. As regards annexin V Römisch et $a l^{12}$ have recently confirmed its antithrombotic effect in an in vivo model of thrombus formation in rats. When investigating bleeding times, they did not find any significant enhancement. For our part, we did not find any tendency to postoperative bleeding in the annexin V-treated eyes. These results remain unexplained and must be confirmed by other studies. However, they would be a very important argument for choosing annexin $\mathrm{V}$ as a prophylaxis for intraocular fibrin in settings with high risks of bleeding, as has previously been suggested for low molecular weight heparin.

Furthermore, annexin $\mathrm{V}$ has an antiinflammatory activity through inhibition of phospholipase $A_{2}$, a key enzyme in the production of inflammatory lipid mediators. Annexin V seems to operate by protecting phospholipids, which are phospholipase $A_{2}$ substrates, from the enzyme activity. Therefore, annexin $\mathrm{V}$ may play a role in our study, not only by preventing fibrin clot formation, as shown by the average fibrin clot at day 1 , but also by inhibiting the inflammatory processes involved in the postoperative reaction. The shorter time to clearing might be explained in part by this effect. This hypothesis is consistent with the recent study of Chan et al. ${ }^{13}$ Working on a model of endotoxin-induced uveitis, the authors found that antiflammins, which are synthetic peptides derived from the sequence of annexin $I$, were efficient in the treatment of phospholipase $\mathrm{A}_{2}$-mediated intraocular inflammation.

Therefore in this study we have shown the potency of annexin $\mathrm{V}$ in reducing fibrin formation in a standardised postoperative model in rabbits. Its efficacy is similar to that of heparin. Annexin $\mathrm{V}$ might be considered as a new therapeutic agent of great interest, since it does not seem to enhance bleeding and acts both on fibrin formation and inflammatory reactions.

This suggests further studies to evaluate annexin $\mathrm{V}$ in humans and to investigate its efficacy in other ocular pathological settings, where both inflammatory reactions and fibrin formation may occur. Annexin V might also be used coated on intraocular lenses, as is the case for heparin. This is of particular interest since fibrin formation is relatively frequent after extracapsular extraction. Spitznas et $a l^{14}$ recently reported that a pronounced fibrinous reaction occurs in $1.9 \%$ of eyes after extracapsular extraction and implantation of a posterior chamber intraocular lens, and that $34.4 \%$ of these patients develop posterior synechiae. Lenses coated with an anti-inflammatory and antithrombotic substance might lower the occurrence of this postoperative outcome.

The authors thank A Minty for his helpful comments, A Labat for technical assistance, and M T Guilhem for editing the manuscript.

1 Johnson RN, Balyeat E, Stern WH. Heparin prophylaxis for intraocular fibrin. Ophthalmology 1987; 94: 597-601.

2 Johnson RN, Blankenship G. A prospective, randomized, clinical trial of heparin therapy for postoperative intraocular clinical trial of heparin therapy for post.

3 Klee CB. $\mathrm{Ca}^{2+}$-dependent phospholipid- (and membrane-) binding proteins. Biochemistry 1988; 27: 6645-52.

4 Burgoyne RD, Geisow MJ. The annexin family of calciumbinding proteins. Cell Calcium 1989; 10: 1-10.

5 Chap H, Comfurius P, Bevers EM, et al. Potential anticoagulant activity of lipocortins and other calcium/ phospholipid binding proteins. Biochem Biophys Res Comm 1988; 150: 972-8.

6 De BK, Misono KS, Lukas TJ, Mroczkowski B, Cohen S. Calcium-dependent 35-kilodalton substrate for epidermal growth factor receptor/kinase isolated from normal tissue. $\mathcal{f}$ Browth factor receptor/kinase is

7 Iverson DA, Katsura H, Hartzer MK, Blumenkranz MS. Inhibition of intraocular fibrin formation following infusion of low-molecular-weight heparin during vitrectomy. Arch Ophthalmol 1991; 109: 405-9.

8 Johnson RN, Olsen K, Hernandez E. Tissue plasminogen activator treatment of postoperative intraocular fibrin. Ophthalmology 1988; 95: 562-95.

9 Williams GA, Lambrou FH, Jaffe GA, et al. Treatment of postvitrectomy fibrin formation with intraocular tissue plasminogen activator. Arch Ophthalmol 1988; 106: 1055-8.

10 Thiagarajan $P$, Tait JF. Binding of annexin V/placental anticoagulant protein I to platelets. Evidence for phosphatidylserine exposure in the procoagulant response of activated platelets. F Biol Chem 1990; 265: 17420-3.

11 Tait J, Sakata M, McMullen B, et al. Placental anticoagulant proteins, isolation and comparative characterization of four members of the lipocortin family. Biochemistry 1988; 27 6268-76.

12 Römisch J, Seiffge D, Reiner G, Päques EP, Heimburger N. In vivo antithrombotic potency of placenta protein 4 (annexin V). Thromb Res 1991; 61: 93-104.

13 Chan CC, Ni M, Miele L, et al. Effects of antiflammins on endotoxin-induced uveitis in rats. Arch Ophthalmol 1991; 109: $278-81$.

14 Spitznas M, Werdermann D, Böker T. Fibrinous reaction occurs until 8 days after intraocular lens implantation. Arch Ophthalmol 1990; 108: 1666. 